\title{
Japanese women in the contemporary society
}

\author{
Violeta Mihaela DINCA \\ The Bucharest University of Economic Studies, Bucharest, Romania \\ violetamihaeladinca@yahoo.fr \\ Teodora FLORICEL \\ The Bucharest University of Economic Studies, Bucharest, Romania \\ Monica Z0TTU \\ The Bucharest University of Economic Studies, Bucharest, Romania
}

\begin{abstract}
The purpose of this paper is to examine Japanese society and present contemporary issues with emphasis on the changes in the role, status and preferences of Japanese women within the Japanese society, through the years. The first part of the paper makes an overview on the evolution of the role of women in Japanese society during Shogunate until now, focusing mainly on increasing Japanese women's status within the enterprise. In the second part of the paper, the author exposes the results of several studies on the effects on the marketing of luxury for Japanese women, highlighting the correlation between increased interest to be as competitive in the workplace and enhancing concern for luxury brands.
\end{abstract}

Keywords: Japanese work force, employment of women, marketing, luxury brands in Japan.

\section{Introduction}

Gender has been an important principle of stratification throughout Japanese history, but the cultural elaboration of gender differences has varied over time and among different social classes. In the twelfth century (Heian period), for example, women could inherit property in their own names and manage it by themselves. Later, under feudal governments (the Shogunate), the status of women declined. Peasant women continued to have de facto freedom of movement and decision making power, but upper-class women's lives were subject to the patrilineal and patriarchal ideology supported by the government as part of its efforts at social control. With early industrialization, young women participated in factory work under exploitive and unhealthy working conditions without gaining personal autonomy. In the Meiji period, industrialization and urbanization lessened the authority of fathers and husbands, but at the same time the Meiji Civil Code denied women legal rights and subjugated them to the will of household heads. Peasant women were less affected by the institutionalization of this trend, but it gradually spread even to remote areas. In the 1930s and 1940s, the government encouraged the formation of women's associations, applauded high fertility, and regarded motherhood as a patriotic duty to the Japanese Empire.

After World War II, the legal position of women was redefined by the occupation authorities, who included an equal rights clause in the 1947 Constitution and the revised Civil Code of 1948. Individual rights were given precedence over obligation to family. Women as well as men were guaranteed the right to choose spouses and occupations, to inherit and own property in their own names, and to retain custody of their children. Women were given the right to vote in 1946. Other postwar reforms opened education 
institutions to women and required that women receive equal pay for equal work. In 1986 the Equal Employment Opportunity Law took effect. Legally, few barriers to women's equal participation in the life of society remain.

\section{Working women in Japan through the years}

As an island nation, Japan historically has long had an ambivalent relationship with the rest of the world. The group orientation of most Japanese is the major characteristic that makes them different from Americans and people in other Western countries. In this paper after a brief general description of the role groups in Japanese life, there are examined all stages of development of the role and status of women in Japanese society. Japan has been historically, and remains without doubt, one of the most group-oriented societies on earth. In the words of the late Harvard professor and famous Japanologist Edwin Reischauer, "Certainly no difference is more significant between Japanese and Americans, or Westerners in general, than the greater Japanese tendency to emphasize the group, somewhat at the expense of the individual" (Reischauer, 1997).

With the passage of time, however, the roles of certain groups and the members within them have changed considerably. Since World War II this has happened within families and the role of women. In contemporary Japan, the role of women within families is changing more dramatically at present than at perhaps any time in history.

Until the mid-twentieth century Japan was primarily a rural nation and extended families were the norm. In traditional Japanese families several generations lived under one roof, wives were clearly subservient to husbands and mothers-in-law, and the large majority of marriages were arranged.

As Japan urbanized and industrialized after World War II, family structure has become much more like the United States and Western Europe. A larger percentage of retired adults in Japan than in the United States still live with or near their children, but the nuclear family is now the norm. Also, Japanese families are having fewer and fewer children than ever before; the statistical average is less than two per household (Ellington, 2012).

Although there are many exceptions, many Japanese still view marriage as an economic arrangement that helps to perpetuate family lines and contributes stability to life. Although the practice has declined in recent decades, some marriages are still arranged by the respective families.

Westerners have often had the most mistaken stereotypes imaginable about Japanese women. In the United States, there has been a recent geisha "boom," which does nothing to dispel the notion that Japanese women's sole mission in life is to please men. Even the popular Western notion of geisha often omits or minimizes the fact that the several thousand true geisha that still ply their trade in Japan go through years of training in classical Japanese music and dancing before attaining that status. The average Japanese woman, while certainly not primarily a passive pleaser of men, is still prone to more discrimination, particularly in the workplace, than is the case in most Western developed countries.

Like women historically in most cultures, Japanese women did not work out of the house. In fact, kanai, the Japanese term that husbands use for their wives, literally means "inside the house." Before World War II women were legally second-class citizens in many ways; they attained equal rights with the adoption of Japan's present constitution. Still, as late as the 1970s most of the Japanese women who worked outside the home did so out of 
economic necessity. During that decade women were still supposed to marry by age twenty-five and have two or perhaps three children.

In the 1970s practicing traditional arts such as playing koto, a stringed instrument; doing ikebana, or flower arranging; or practicing the tea ceremony was the most acceptable way for a middle-class woman to spend her leisure time. By the 1980s Japanese attitudes had changed to the point that it was socially acceptable if middle-class women worked part time.

By the 1990s and 2000 massive numbers of women were entering the Japanese workplace, changing their own lives and the Japanese family as well.

Viewing the population of 15 years old and over as of October 1st, 2007 (110,302 thousand) in terms of their normal labor force status, persons engaged in work numbered 65.978.000. The national statistics bureau publishes reports on the labour force every five years. The report for 2017 is not yet ready so we will take into account for analysis those published in 2007 and 2012.

Between 2007 and 2012, the persons engaged in work decreased by 1,557 thousand to 64,421 thousand, while persons not engaged in work increased by 2,070 thousand to 46,394 thousand. Viewing persons engaged in work by sex, males numbered 36,745 thousand and females 27,676 thousand. In 2012, compared to 2007, males decreased by 1,430 thousand (3.7\%) and females by 127 thousand (0.5\%), it can be observed that the decrease for males exceeding that for females. Regarding persons not engaged in work by sex, males numbered 16,669 thousand and females 29.726 thousand. It is easy to see that the number of unemployed women is higher than men's number. On this line, in 2012, compared to 2007, males not engaged in work increased by 1,562 thousand (10.3\%) and females not engaged in work by 510 thousand (1.7\%), the increase for males exceeding the one for women (Table 1).

Table 1. Population of 15 years old and over by sex and labour force status / 2007,2012

\begin{tabular}{|c|c|c|c|c|c|c|}
\hline \multicolumn{3}{|c|}{$\underbrace{\text { Labour force status }}_{\text {sex }}$} & $\begin{array}{c}\text { Population of } \\
15 \text { years and } \\
\text { over }\end{array}$ & $\begin{array}{l}\text { Persons } \\
\text { engaged in } \\
\text { work }\end{array}$ & $\begin{array}{c}\text { Persons not } \\
\text { engaged in } \\
\text { work }\end{array}$ & $\begin{array}{l}\text { Ratio of } \\
\text { persons } \\
\text { engaged in } \\
\text { work }\end{array}$ \\
\hline \multirow{6}{*}{ 离 } & Both sexes & 2012 & $110,815.1$ & $64,420.7$ & $46,394.4$ & 58.1 \\
\hline & & 2007 & $110,301.5$ & $65,977.5$ & $44,324.0$ & 59.8 \\
\hline & Male & 2012 & $53,413.2$ & $36,744.5$ & $16,668.7$ & 68.8 \\
\hline & & 2007 & $53,282.5$ & $38,174.8$ & $15,107.8$ & 71.6 \\
\hline & Female & 2012 & $57,401.9$ & $27,676.2$ & $29,725.7$ & 48.2 \\
\hline & & 2007 & $57,018.9$ & $27,802.7$ & $29,216.2$ & 48.8 \\
\hline \multirow{3}{*}{ 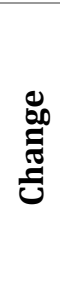 } & Both sexes & Number & 513.6 & $-1,556.8$ & $2,070.4$ & - \\
\hline & & $\begin{array}{l}\text { Increase- } \\
\text { decrease } \\
\text { rate }\end{array}$ & 0.5 & -2.4 & 4.7 & -1.7 \\
\hline & Male & $\begin{array}{l}\text { Number } \\
\text { Increase- } \\
\text { decrease }\end{array}$ & $\begin{array}{c}130.7 \\
0.2\end{array}$ & $\begin{array}{c}-1,4303 \\
-3,7\end{array}$ & $\begin{array}{c}1,560.9 \\
10.3\end{array}$ & -2.8 \\
\hline
\end{tabular}




\begin{tabular}{|c|c|c|c|c|c|c|}
\hline & rate & & & & \\
\cline { 2 - 6 } & Female & $\begin{array}{c}\text { Number } \\
\text { Increase- } \\
\text { decrease } \\
\text { rate }\end{array}$ & 0.7 & -126.5 & 509.5 & - \\
\hline
\end{tabular}

Source: http://www.stat.go.jp/english/data/shugyou/pdf/sum2012.pdf.

Table 2. Ratio of persons engaged in work by sex and age group / 2007, 2012

\begin{tabular}{|c|c|c|c|}
\hline$x^{2}$ & \multicolumn{3}{|c|}{ Female } \\
\hline Age & 2012 & 2007 & Change \\
\hline Total & 48.2 & 48.8 & -0.6 \\
\hline 15 to 19 years old & 16.5 & 17.3 & -0.8 \\
\hline 20 to 24 & 66.6 & 68.4 & -1.8 \\
\hline 25 to 29 & 75.3 & 73.5 & 1.8 \\
\hline 30 to 34 & 68.2 & 63.5 & 4.7 \\
\hline 35 to 39 & 67.1 & 64.6 & 2.5 \\
\hline 40 to 44 & 70.7 & 71.1 & -0.4 \\
\hline 45 to 49 & 74.6 & 74.6 & 0.0 \\
\hline 50 to 54 & 73.2 & 70.9 & 2.3 \\
\hline 55 to 59 & 65.0 & 61.5 & 3.5 \\
\hline 60 to 64 & 47.3 & 43.5 & 3.8 \\
\hline 65 to 69 & 29.8 & 28.1 & 1.7 \\
\hline 70 to 74 & 18.0 & 17.7 & 0.3 \\
\hline 75 years old and over & 6.3 & 6.7 & -0.4 \\
\hline $\begin{array}{l}\text { (Reclassified) } \\
15-64 \text { years old }\end{array}$ & 63.1 & 61.7 & 1.4 \\
\hline
\end{tabular}

Source: http://www.stat.go.jp/english/data/shugyou/pdf/sum2012.pdf.

As we can see in Table 2, in 2012, compared to 2007, the ratio decreased in all age groups for female. The most significant growth is found in the group of 30 to 40 with $4.7 \%$. Even so, a large number of married women still stop working when they have children. Recent employment rates of married women whose youngest child is below the age of three is 28.2 percent. The rate goes up as the age of the youngest child increases, reaching 72.7 percent among married women whose youngest child is age 12-14 (Ellington, 2012).

Even though almost half of all Japanese women work out of the home, a higher percentage of women have part-time jobs than in the West, and the ratio of part-time to full-time workers is highest among women with children. On average, women only earn about 60 percent of the money than men get for the same type and amount of work. It is also, with some exceptions including education and fashion, still difficult for female graduates of universities to obtain jobs commensurate with their educational levels. The majority of large Japanese companies do not make managerial positions available to women university graduates because of a belief that upon becoming mothers, women will devote more time to child-rearing than work. There does seem to be some progress, however, in the earning power relative to men of women under thirty, as recent statistics indicate women in this age cohort now earn 86 percent the hourly wages of their male peers.

The following graphs (Graph 1 and Graph 2) present the trends in number of persons engaged and not engaged in work by sex, between 1982 and 2012. 
Graph 1. Trends in number of persons engaged in work by sex

(thousand persons)

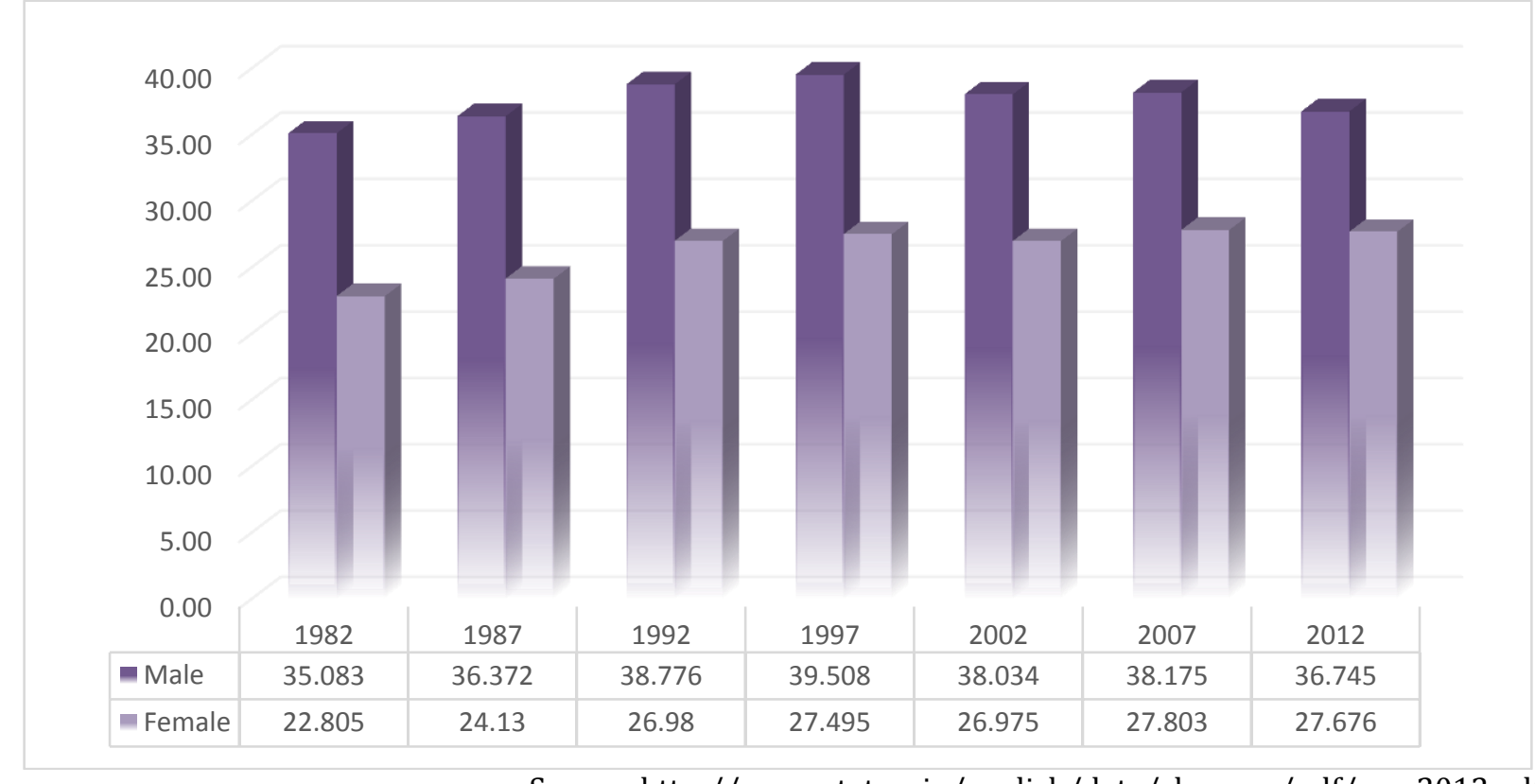

PICBE | 611

Charts show a slow increase in the number of Japanese women employed between 1982 and 2012, and also the trend in number of female not engaged in work is positive. Although small, the number of women in the workforce with managerial and professional responsibilities is definitely increasing.

Graph 2. Trends in number of persons not engaged in work by sex

(thousand persons)

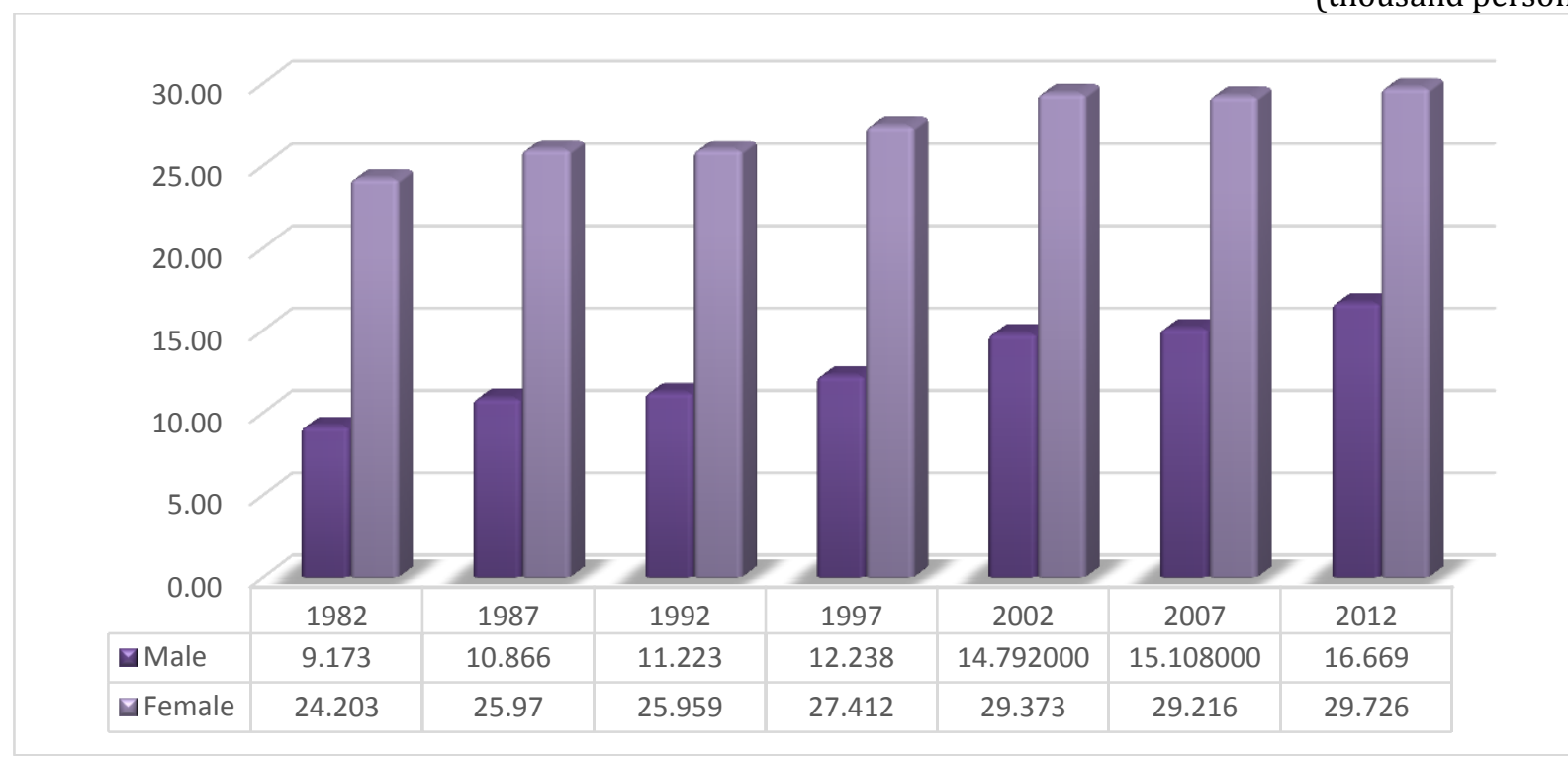

Source: http://www.stat.go.jp/english/data/shugyou/pdf/sum2012.pdf.

This is partially due to the implementation of the Equal Employment Opportunity Law in 1986, which established a two-track system for female job applicants. Women seeking a general-track job are treated separately from men. General-track jobs are 
normally less demanding and have limited opportunities for overtime pay and promotion, but women in this track need not worry about being transferred to a different area. Integrated track jobs for women place them in the same category as men, meaning they are subject to transfers, promotion, and overtime pay. Although progress can be attributed to the categorization portion of the law, the statute also reflects the still deeply held Japanese view that women in the workplace are special cases. Only women are given two tracks from which to choose. Men are expected, because they are male, to be in the integrated track.

Still, many working females are typically young unmarried women, for whom the Japanese have a nickname that may be translated as "office ladies." These young women work for a corporation for five to six years after they graduate from high school, or junior college, and upon marrying are expected to leave the company. Japanese view these work years for a woman as a time she can learn about the world before settling down.

Office ladies are never given meaningful work but instead are expected to create a pleasant environment for the permanent, mostly male employees by making and serving tea and running errands. Many executives in Japanese companies feel obligated to help their young male employees find wives. Management often views the pool of office ladies as a good source of brides for these young men.

Until quite recently, the almost universal expectation of a married Japanese woman was that her important role was not marketplace work but child rearing and home management.

Traditionally Japanese housewives have done virtually all household chores, and despite some societal rhetoric, this largely still seems to be the case today. Although husbands can be major actors in deciding big-ticket household expenditures such as automobile purchases, wives have traditionally controlled family budgets, and it is not uncommon for wives to give their husbands an allowance! In addition to the added pressure of often having a part-time or full-time job and no real help at home, many married women today have a new burden: the care of a fast-growing elderly population. There are clear signs in contemporary Japan that many young women look at married life and have ambiguous feelings about its respective costs and benefits. The average age for a first marriage for Japanese women is now slightly below twenty-eight, and as of the late 1990s, almost 50 percent of Japanese women in their twenties were not married. By comparison, in the 1980s, only 30 percent of the same female cohorts were unmarried (Ellington, 2012). Young Japanese women seem to be enjoying the freedom afforded by income from the workplace and foregoing the tremendous responsibility Japanese society has placed upon married women.

Though the increase in the average age Japanese women marry and the drop in fertility are clear signs that attitudes about women's lifestyles are changing, it is too extreme a position at this time to imagine that all young Japanese women are unhappy with traditional female roles. Many Japanese women still enjoy the housewife role that brings power over family finances, and after the children are old enough for school, leisure and recreation time. Also, women who do work often do not encounter the pressure that their male counterparts confront in Japanese companies, including the de facto requirement to spend evening leisure time with work mates.

Japanese attitudes about gender, the family, and the workplace, despite changes, remain different in many ways than dominant Western positions. Even though there are neutral alternatives, one of the most common words Japanese wives use when referring to 
their husband is shujin, or master (of the house). One recent survey of almost 200 whitecollar and educated women from three different Japanese urban areas found that 89 percent used either the term shujin (my/our master) or uchi no shujin (master of the house) when addressing their husbands.

\section{Marketing, brands and Japanese women - an approach for the 21st century}

In the next section of the paper we want to present several studies in order to highlight the fact that the Japanese, especially Japanese women in the last two decades have become very concerned about the effects of marketing when referring to trends and brands. Japanese reputation, particularly the females who like to purchase accessories rose to a very high degree. Japan is the world's most concentrated area of global revenue for high end goods. There are a lot of things that are unique for Japan and Japanese marketing such as the extravagance of Japanese commercials and also the need to make everything cute.

We need to talk about the origin of luxury, that it goes back to the dawn of humanity. The word luxury derives from the Latin 'luxus' which can be translated as "superfluous abundance". The desire for luxury generates an inevitable commitment to the growth of wealth and brings with it of course, an increase and differentiation of wants. For the great majority of the people, those able through their heritage or personal effort to obtain luxury generate a mixture of envy and approval as role models.

In the early 1970s Japan's GDP has been increasing at an average of 9.5 percent per year with per capita income and reached that of Western Europe. In that period, the Japanese tourists became observable, especially in Europe. The opportunity was seen by the French, Italian and Swiss luxury houses to start setting up sales branches in Japan. In this regard, Gucci opened its first site in 1972 in Tokyo, while Louis Vuitton did the same thing in 1978. The Japanese became rapidly the driving force behind the maximization of luxury fashion retail all over Asia.

In Japan, the only way to shine in egalitarian society is to demonstrate a superior "savoir-faire". The Japanese women are amazingly diligent readers and followers of luxury fashion magazine. They want to let their social group know that they have a sophisticated taste of luxury fashion. We must mention the fact that the Japanese women have an extremely status in what is typically a male-dominated society. At home Japanese women have to serve their husbands, at work their bosses. As result, for them buying luxury fashion goods becomes a substantial statement of their existence, and a really power. The luxury stores in Japan are the only places they are respected and cherished. A raison why Japanese women go to shopping is just to experience the feeling of being served.

We are going to present the results of a study which proves that high end goods sell well among Japanese women. The study focuses on Japanese women living in the Tokyo metropolitan area aged between 20 and 60 years. Of the 480 respondents, approximately $60 \%$ show a high interest for brands. Only $8.6 \%$ have no interest in buying branded products. The study was also directed towards women in the whole population, not to those who get a higher income or a higher financial state. However, of all the women surveyed, $43 \%$ have purchased at least once a product brand Louis Vuitton. Regarding the Gucci brand products, the percentage is $41 \%$. Even luxury jewelry maker Tiffany recorded a 
buying rate of $38 \%$. Burberry won first place in the list with $50 \%$ of respondents buying at least one product of this brand.

Of the women surveyed $40 \%$ were housewives and $9 \%$ were either part time workers or unemployed. This must mean many husbands spend a lot of money on their wives. But even if these women work and they want to purchase a reasonable priced purse or accessory, they are stretched to the limits since the women do not make enough income for these commodities. Working or not, brands are the way to be in Japan. The Japanese culture does not limit to a particular product or the line; it is about targeting the consumer and going above and beyond to cover as many parts of their lifestyle needs. Many stores carried clothing, but now the brands are selling CDs, furniture, cosmetics, and they are still selling shoes and accessories to attract a bigger clientele (Antram, 2007).

These facts have determined analysts to arrive at the conclusion that Japanese women are choosing to marry later in life and there are a large number of young working women living with their parents. With a big amount of disposable income, they express their personality in luxury brands. In fact, $70 \%$ of the luxury products sold in Japan are purchased by $10 \%$ of the population, primarily unmarried women living with their parents (Boatman, 2016).

We will examine this feature further by noting that no other country in the world is as concentrated a source of revenue for so many luxury brands as Japan. Here, a population not even half as large as that of the United States consumes an incredible 41 percent of the entire world's luxury goods.

This appetite makes Japan the source of a striking percentage of revenues for many of the world's luxury brands. The following chart shows the percentage of each company's overall revenue that is generated in Japan.

Table 3.Percentage of overall revenue from Japan

\begin{tabular}{|c|c|}
\hline Baccarat & $\mathbf{3 5 \%}$ \\
\hline Bulgari & $26 \%$ \\
\hline Burberry & $36 \%$ \\
\hline Coach & $22 \%$ \\
\hline Hermes & $25 \%$ \\
\hline Gucci Group & $27 \%$ \\
\hline LVMH Group & $15 \%$ \\
\hline Louis Vuitton brand & $+30 \%$ \\
\hline Salvatore Ferragamo & $27 \%$ \\
\hline Tiffany \& Co. & $20 \%$ \\
\hline Van Cleef and Arpels & $33 \%$ \\
\hline
\end{tabular}

Source: http://www.jetro.org/content/361

For instance Bulgari's CEO Francesco Trapani pointed out that "accounting for 26\% of total revenues, Japan is for Bulgari the first and most important market." Japan is also the single largest market for Baccarat, Burberry, the Gucci Group, Louis Vuitton and Salvatore Ferragamo and is the second largest market for Coach and Tiffany \& Co.

Regarding facial expressions in commercials, the Japanese tend to focus on the eyes whereas Americans focus on the mouth. This may explain the difference between Japanese and Western emoticons where the Japanese ones focus more on the eyes while generally in western communication the focus is in smiling or frowning. In Japanese advertisements the 
models/actors usually bear a more neutral look on their face than in American ones where the model is likely to have an over exaggerated smile on their face so as to convey the amount of happiness you will experience using the product that is being advertised (Yuki et al., 2007).

It is clear that the Japanese have something different in the approach of marketing brand compared to what is usually seen in Europe and United States. The marketing brand in Japan must construct ideas and practices in order to keep their culture intact.

\section{Conclusion}

Although the twelfth century, during the Heian era Japanese women could own and manage property in their own land, starting with the Shogunate period the status of women in Japan declined until the end of the Second World War. In the second half of the twentieth century, there were several reforms and the situation of women in Japanese society has improved. It should be stressed that although the number of female employees increased from year to year, the number of women occupying managerial positions in Japan is still quite low compared with other developed countries. During the twentieth century the economic landscape of Japan changed and influenced the creation of specific market strategies and raised the standards of Japanese quality production. Yet even if Japanese women are working or not, in recent decades there is an increased tendency in their preferences for luxury brands that turned Japan into a place where many luxury brands attract a good part of their earnings annually. It remains to be seen how the current economic climate will affect the Japanese woman's concern to develop professionally, just as the effect of this conjecture on female predilection for luxury brands.

\section{References}

Antram, N., (2007). The obsession with brands, GMO Research Blog: Japan Marketing Review. Retrieved from GMO Research Blog: http://www.gmo-research.jp/mt/nick/.

Boatman T. (2016). Ginza Brand Central for Luxury. Retrieved from http://www.gonative.jp/articles/ginzaground-zero-for-luxury-brands.

Ellington, L. (2012). Japan: a global studies handbook, Publisher: ABC-CLIO, Santa Barbara, California, ISBN-13: 978-1576072714, 163-171.

Reischauer, E.0. (1997). Japanese, Harvard University Press, ISBN: 0674471768, 134-147.

Japan is the world's most concentrated source of revenue for luxury brands. Retrieved from http://www.jetro.org/content/361.

Ronald J.D. (2009). International School of Management Paris, 2009.

Japan's Statistics Bureau \& Statistics Center, (2012). Employment structure of the population of 15 years old and over and households. Retrieved from http://www.stat.go.jp/english/data/shugyou/pdf/sum2012.pdf.

Yuki, M., Maddux, W.W. and Masuda, T. (2007). Are the windows to the soul the same in the East and West? Cultural differences in using the eyes and mouth as cues to recognize emotions in Japan and the United States, Journal of Experimental Social Psychology, 43, 303-311. 